\title{
A COMPLEX APPROACH ON INTEGRATED LATE BILINGUALS’ ENGLISH VOT PRODUCTION: A STUDY ON SOUTH BRAZILIAN IMMIGRANTS IN LONDON
}

\author{
Felipe Flores Kupske* \\ Universidade Federal da Bahia \\ Salvador, BA, BR
}

\begin{abstract}
Adopting a Complex perspective to language, this study explores the correlation between length of residence (LOR) in London and the production of word-initial English voiceless stops by late south Brazilian bilinguals who have an integrative motivation towards the host language and culture. To this end, 12 immigrants are compared to 10 standard southern British English monolinguals. Acoustic analysis of VOT duration is reported. Results demonstrated that immigrants' VOT values for English are positively correlated with LOR. Bilinguals with the longest LOR revealed a production of English VOT within the range expected for the controls. These findings can be interpreted as evidence for language as a Complex Adaptive System, and for the hypothesis that the neuroplasticity and the cognitive mechanisms for language development remain intact during the lifespan.
\end{abstract} Keywords: Late Bilingualism; Complexity Theory; Immigration; VOT.

\section{Introduction}

Second language (L2) research has already recognized that there is an inverse correlation between age of L2 development and level of ultimate achievement, as the older speakers are at the onset of bilingualism, the less inclined they are to gain native-like proficiency (Schmid, Gilbers, \& Nota, 2014). Therefore, for the development of the L2 phonemic system earlier is better as far as the onset of bilingualism is concerned (e.g., Flege, Schirru, \& MacKay, 2003; McCarthy, Evans, \& Mahon, 2013). However, to de Leeuw (2014), in spite of the fact that usually "a language acquired early in life is done more 'successfully' than a language learned late in life, there is, in principle, nothing which categorically prevents a late L2 learner from achieving the same level of proficiency in an L2 as a native speaker" (de Leeuw, 2014, p. 34). Following that angle, there is a robust body of research suggesting that it is possible for late bilinguals to attain native levels in their L2 speech production and perception, as in the studies conducted by Bongaerts, Summeren, Planken, and Schils, (1997), Sancier and Fowler (1997), and Muñoz and Singleton (2007) in which late bilinguals yield L2 production within the same range of the L1-controls. Those studies, for instance, validate Flege $(1995,2007)$ and Best and Tyler (2007) who propose that the cognitive mechanisms for language development remain intact during the lifespan, and that even late bilinguals would be able to reach L2 native-like levels.

A recent angle to comprehend L2 speech development may be noticed in complex approaches (e.g., de Bot, Lowie, \& Verspoor, 2007; Larsen-Freeman \& Cameron, 2008; Beckner et al., 2009; Kupske, 2016), in which language is seen as a Complex Adaptive System (CAS), and language development as being the result of "interrelated patterns of experience, social interaction, and cognitive processes" (Beckner et al., 2009, p. 2). These approaches accommodate the fact that late bilinguals are able to attain native-like

\footnotetext{
* Professor in the Department of Germanic Languages at Federal University of Bahia - UFBA. His activities address the development and the interaction between speech perception and production, drawing on ideas from sociophonetics and experimental phonetics. His current research aims to investigate how bilingual speakers change their abilities to produce and perceive their L1 in L2 ᄀ-dominant settings. He received his doctor's degree in Linguistics from the Federal University of Rio Grande do Sul (UFRGS), Brazil, in 2016. His email address is kupske@gmail.com
} 
production in their L2 under certain circumstances, as to Herdina and Jessner (2002), de Bot et al. (2007), and to Beckner et al. (2009), languages are not rigid systems, and the level of L2 proficiency depends on a fusion and interaction of a considerable number of factors, such as, input (quality, frequency, recency etc.), education, motivation, language attitudes, age and so on.

For immigrants in an L2-dominant setting, focus of this study, one of the factors that explicitly has an effect on L2 speech development is the length of residence (LOR) in the host country (e.g., Rasinger, 2005; Stevens, 2006; Kupske, 2016), as it correlates with L2 proficiency in terms of native-speaker likeness (e.g., Johnson \& Newport, 1989; Birdsong, 2005), and is also associated with a good L2 use (Chiswick \& Miller, 2001; van Tubergen \& Wierenga, 2011). To Johnson and Newport (1989) and to Birdsong (2005), immigrants are able to achieve native-like production in a span of five and ten years, respectively. However, according to van Tubergen (2010), the effect of LOR is prone to be no longer representative after ten years of immigration. In addition, favorable and unfavorable attitudes towards the L1 and the L2 play a significant role in acculturation and language development, as, for instance, positive attitudes towards the host language and culture-integrated acculturation attitudes/ integrative motivation-would facilitate learning (Yilmaz \& Schmid, 2015). On the other hand, Ellinger (2000) reveals a negative correlation between L2 proficiency and L1 language and culture adherence, as the L1 use and the preservation of robust connections with the first language and culture are recognized to hinder L2 cultural and linguistic integration (Chiswick \& Miller, 2001; Yilmaz \& Schmid, 2015) and, as a consequence, L2 development.

In this perspective, using a cross-sectional design for the collection of the corpus, this study addresses the production of English-L2 VOT by integrated Brazilian immigrants (late arrivals; age of arrival $>20$ years) in a complex perspective. The goal of this study is twofold. Firstly, it aims at exploring the correlation between LOR in London and the production of word-initial English voiceless stops by late Brazilian bilinguals who have an integrative motivation towards the host language and culture, and who have had less than eleven years of LOR at the testing. Secondly, it also intends to investigate whether integrated adult immigrants differ from English controls or achieve the ultimate attainment in the L2-VOT production, as reported by Major (1992) and Sancier and Fowler (1997).

To Major (1992), the VOT in Brazilian Portuguese (BP) is significantly shorter than in English; therefore, our core hypothesis is that immigrants' VOT duration for English-L2 will increase as LOR in London increases, due to the fact that initially $\mathrm{BP}$ phonemic categories will be used for the L2 speech production, and that participants with the longest LOR will yield the longest VOT values, possibly reaching a native range of production. At the same time, by applying a complex frame of reference to the immigrants' data, this paper also seeks to provide empirical evidence to corroborate Beckner et al. (2009), Herdina and Jessner (2002), Flege (1995), and Best and Tyler (2007) who argue against the view that L1 is contrasting to L2 development and advocate that the neuroplasticity and the same mechanisms and processes operate on L1 as on the L2.

To that end, this paper is organized as follows. Firstly, our theoretical background is presented, in which we discuss a complex angle to language development, and our object of analysis-VOT. After that, the methodology of the study is described, in which we delineate the study's participants, materials and procedures. We finalize this work with our discussion and conclusions, addressing and advocating language as a CAS.

\section{Theoretical Framework}

\subsection{Principles of complex approaches to lan- guage development}

In a few words, a complex perspective to language describes holistic, organic, and emerging systems that are composed of two or more interrelated systems, which may per se represent other complex systems (Mercer, 2013). To Opitz (2013), a basic tenet of complex approaches is the interconnectedness and nonlinear interaction of all elements within a system and 
with its environment. Barriers between systems are no longer clear, since a system is usually also a part of other systems (Kupske \& Alves, 2016), and all agents/(sub) systems of a system are at the same time influencing and being influenced by all the others.

To Willians (1997), a complex system is everything that moves, changes, or evolves over time, and during these dynamic processes, agents learn from each other, receive feedback, and gain experience. This is the point at which its components create something larger than they would individually; a structure without divisible components and whose connectivity is (should be) permanent (Kupske, 2016).

According to Mercer (2013), these systems are self-structuring and self-sustaining, with an ability to constantly adapt according to the environment and to the energy received or expended. To Larsen-Freeman and Cameron (2008), they are adaptive, such that a change in one element or part of the system leads to changes in its overall configuration. In addition, their behaviors or changes are not proportional to their causes, as a small variation in the system or a small entrance of new energy can bring about great and unpredictable changes. CAS are open systems and, as a consequence, energy can either enter or exit them.

Therefore, to Beckner et al. (2009, p. 1), language is a CAS because (i) it consists of multiple agents that interact with one another (e.g., speaker in a given community or context); (ii) behaviors of its speakers are based on their past interactions, that alongside current ones will delineate the future interactions; (iii) behaviors of its speakers are consequences of competing factors, ranging from perceptual restrictions to social motivations; and (iv) that its structures emerge from interrelated patterns of experience, social interaction and cognitive mechanisms.

With regard to language development, it is known that the patterns of use, as pointed out, for example, by usage-based models (e.g., Bybee, 2001), affect how a language is developed, used, organized and even how it is able vary during the life of an individual. As a consequence, changes in both L1 and L2 proficiency should match with changes in language use, such as in opportunities to practice them and to access natural input (Opitz, 2013). For that reason, various scholars (e.g., Ellis, 2008; Herdina \& Jessner, 2002; Kupske, 2016) argue that the nature of language development in a complex perspective is probabilistic and sensitive to frequency of language use/contact.

Usage-based theories then provide the complex research with a direction, advocating that a speaker learns constructions and linguistic categories by engaging in organic communication through interpersonal and cognitive processes (Slobin, 1977). To Beckner et al. (2009), language development involves the estimate of the norms of a given speech community through a complex and probabilistic analysis of limited language samples derived from experiences perceived by speakers' cognitive machinery, psychomotor capacities, as well as by the dynamics of social interaction itself. A linguistic system then results from complex cycles that involve language use, linguistic change, perception and learning of the interactions between members of a speech community (Ellis, 2008), as already indicated. For the L2, its constructions are closely related to frequency, recency and to its context of use itself. According to Larsen-Freeman (1997, p. 62), as for the L1, learners not only conform to the L2; they go further, building new forms through analogies and recombination of patterns during organic interaction. It is the sequential processing, planning, and categorization skills that enable them to build linguistic systems. However, these skills intrinsically do not demand an effective language use; people need to speak as a result of social interaction. Thus, although language is shaped by cognitive abilities, it is the social life that ends up demanding what is understood by language.

For Haugen (2001), languages are constantly being redesigned by the interactions of their speakers in order to reflect the communicational experiences of the past, and to project current and future ones. Thus, any behavior of a speaker is the result of a range of competing factors, including physical as well as cognitive and social motivational ones. Over time, social interactions between speakers/agents produce linguistic changes at all levels, since there is a relationship among individuals and the environment, which provides patterns (samples) to be followed (Gibson, 1979). From this perspective, 
linguistic constructions are developed by means of real communicative acts through interpersonal processes, in addition to the cognitive processes already mentioned. Thus, the development and the cognitive organization of a language are directly driven by the linguistic experience of a speaker in a given speech community.

\subsection{Voice Onset Time}

Voice Onset Time (VOT) can be defined as the interval regarding the delay of the vibration of the vocal folds between the stop release and the start of the following vowel sound (Lisker \& Abramson, 1964; Ladefoged, 2001; Cohen, 2004). VOT is usually divided into three categories: (i) Zero VOT: vocal folds vibration starts at the moment of the stop release, with a duration between 0 and $+35 \mathrm{~ms}$; (ii) Positive VOT: vocal folds vibration starts with a delay after the stop release, this delay being a moment of voiceless aspiration with a duration superior to $+35 \mathrm{~ms}$; and (iii) Negative VOT: vocal folds vibration starts before the stop release, sometimes referred to as pre-voicing, with values ranging between $-125 \mathrm{~ms}$ and $-75 \mathrm{~ms}$ (e.g., Lisker \& Abramson, 1964; Schwartzhaupt, 2015).

Although there is no absolute measure for VOT values for each voiceless stop, Lisker and Abramson (1964) point out that the typical values for English are around $80 \mathrm{~ms}$ for $/ \mathrm{k} /{ }^{1}, 70 \mathrm{~ms}$ for $/ \mathrm{t} /$, and $58 \mathrm{~ms}$ for $/ \mathrm{p} /$. As for BP, according to Kupske (2016), the VOT values vary from $39 \mathrm{~ms}$ for $/ \mathrm{k} /, 18 \mathrm{~ms}$ for $/ \mathrm{t} /$, and $15 \mathrm{~ms}$ for $/ \mathrm{p} /$. Therefore, in BP, voiceless stops are produced with a Zero VOT, while in English they are produced with positive one, and are also aspirated: $\left[\mathrm{p}^{\mathrm{h}}\right],\left[\mathrm{t}^{\mathrm{h}}\right]$, and $\left[\mathrm{k}^{\mathrm{h}}\right]$. In other words, the two languages belong to distinct VOT groups due to their differences of voicing patterns.

\section{Materials and method}

\subsection{Participants ${ }^{2}$}

For the experimental group, twelve south Brazilian immigrants, native speakers of Southern BP, 6 female and 6 male, living in London were recruited as volunteers, and reported no speech, hearing, or language difficulties. ${ }^{3}$ They were all born in Porto Alegre, Rio Grande do Sul, and had arrived in the UK after the age of 20 , representing a group of first generation immigrants. At the recruitment, participants were aged between 20 and 51 years (Mean $=26.90$ years of age, $\mathrm{SD}=7.3$ years), and had lived in London for different periods of time ranging from 8 to 122 months $($ Mean $=63.50$ months, $\mathrm{SD}=41.03$ months). They were also grouped into three categories (experimental subgroups) according to their LOR in years in the United Kingdom: LOR 0-3 years; LOR 4-7 years; and LOR 8-11 years. Even though L2 proficiency may be influenced by the variables age and age at testing, these variables correlate to LOR (Schmid, 2011) here investigated and are not controlled, as the longer the LOR, the greater the age and age at testing. However, participants should be over 20 years of age at the immigration to London, age of arrival (AOA).

Participants' proficiency was controlled by the C-Test (Keijzer, 2007) as all of them should be proficient or near proficient in English at the testing. Information on personal background, language use (contact) and cultural and attitudinal orientations was collected by means of an in-depth sociolinguistic questionnaire with 81 questions (Kupske, 2016) to guarantee that none of the participants had been to England prior to immigration, and that their English was rudimentary, if existent at all, upon arrival in London. We also consider their AOA to be the onset of bilingualism as English was consecutively developed during the immigration, and by means of no formal instruction. In the questionnaire, participants were also presented with a list of interlocutors (e.g., when talking to parents or friends) and social situations (e.g., at work or at home) and, for each interlocutor or situation, they had to state whether they used English only, BP only, or whether they varied between English and BP. A further group of questions related to the participants' cultural orientations and attitudes towards their L1 and L2 communities was provided. For instance, following Yilmaz and Schmid (2015), they were asked about the cultures and languages they felt more comfortable with, which language they preferred to speak, whether they felt themselves more Brazilian 
or British, and whether they felt homesick or had any regrets immigrating to London. For all these questions, participants should choose an option in a scale that was later converted into a value. For example, with regard to language use, they had to choose: never L1/ always $\mathrm{L} 2=0$; seldom L1 and mainly L2 $=.25$; half the time $\mathrm{L} 1$ and half the time L2 $=.50$; mainly L1 and seldom L2 = .75; and only L1 never L2 $=1$. Following Schmid (2011) and based on the responses, means for L1 and L2 use and attitudes were calculated. Only participants with integrated attitudes and with similar means to L1 and L2 use were considered, so that we could focus on the analysis of LOR.

As for the Standard Southern British English (SSBE) control group, ten monolinguals, aged between 20 and 47 years old (Mean $=24.30$ years, $S D=6.64$ ), 5 males and 5 females, were also invited. The SSBE speakers were all born in the south of England, and resided in London at the testing.

All participants were invited to fill out and sign an Informed Consent Form, and also had the right to stop taking part in the testing at any time. Informants identities were kept confidential, as identification numbers were assigned to each one of them.

\subsection{Stimuli and apparatus}

With regard to the vocalic context, Cohen (2004) highlights that just vowel height has an effect on the duration of the preceding stop. Our choice of vowel contexts then takes into account the studies by Cohen (2004) and Bohn and Flege (1993). It is important to note that residents of Porto Alegre, Brazil, tend to palatalize $/ \mathrm{t} /$ and /d/ before the high vowel [i], and words like "tia" (gloss: aunt) and "dia" (gloss: day) are pronounced as [' $\mathrm{t} f \mathrm{ie}$ ] and ['dzir], respectively, with initial affricates instead of stops. In addition, both affricates are not phonemes in BP and just come to light in that specific context. For that reason, items with the high vowel [i] were excluded from the stimuli group. Thus, this study takes into account 18 targets with word-initial stops preceding high and low back vowels and 6 distractor items, totaling 24 items, as presented in Table 1.
Table 1. Target stimuli in English

\begin{tabular}{llll}
\hline$/ \mathrm{p} /$ & $/ \mathrm{t} /$ & $/ \mathbf{k} /$ & Distractors \\
\hline poodle & tool & cool & lap \\
poof & toot & coop & not \\
pool & tooth & coot & lick \\
pop & tod & cob & short \\
posh & top & cod & rat \\
pot & toss & cop & thin \\
\hline
\end{tabular}

All recordings were made in specific recording booths at the Chandler House (Division of Psychology and Language Sciences, University College London, London, England), using software Adobe Audition 2.0 for Windows and a Rote NT1/1 professional microphone with a sampling rate of $44.1 \mathrm{kHz}, 16$-bit resolution. Targets were recorded in stereo and then converted to mono with the same software. The author conducted all recording sessions in English to minimize any bias of language mode/shift.

\subsection{Procedure}

Target items were presented on a computer screen, and were named in the carrier sentence I would say Participants recorded all targets in randomized orders three times. Therefore, the data collection was divided into three blocks containing the same targets, but with different orderings. Each participant recorded a different order of items, and was instructed to read the carrier sentences in a normal and constant speech rate. They could repeat any target if necessary, and also could make short pauses when needed. VOT duration was measured manually from the stop burst to the onset of voicing. In case of multiple bursts, the last one was considered the initial point for the measurement. Acoustic measurements were made in Praat (Boersma \& Weenink, 2016).

\section{Results}

The results of this study are presented in two sections. In section 3.1, the results for the SSBE control group are described; and, in 3.2, the results for the experimental group are presented as well as 
our inferential statistical analysis comparing it to the monolingual controls.

\subsection{SSBE control group}

For the production of /p/ in English, a mean VOT value of $62.52 \mathrm{~ms}(\mathrm{SD}=14.46 \mathrm{~ms})$ was found, with a range between 25.96 and $90.96 \mathrm{~ms}^{4}$ This value is very close to the one pointed out by Lisker and Abramson (1964), a round value of $58 \mathrm{~ms}$, ranging from $20 \mathrm{~ms}$ to $120 \mathrm{~ms}$. On the other hand, the value of our control group differs from the round $42 \mathrm{~ms}$ pointed out by Docherty (1992) for the British English.

For $/ \mathrm{t} /$, the VOT mean value found was $78.85 \mathrm{~ms}$ $(\mathrm{SD}=17.56 \mathrm{~ms}$ ), with a range between 31.59 and 113.37 ms. Again, this value is close to the one of Lisker and Abramson (1964) for English, a round value of $70 \mathrm{~ms}$, ranging from $30 \mathrm{~ms}$ to $150 \mathrm{~ms}$. Moreover, this average is quite close to the $76 \mathrm{~ms}$ round figure raised by Chao and Chen (2008). As for the bilabial stop previously seen, again, the overall mean presented by our data is higher than the $64 \mathrm{~ms}$ signaled by Docherty (1992), ranging between $30 \mathrm{~ms}$ and $110 \mathrm{~ms}$.

Finally, for $/ \mathrm{k} /$, the VOT mean value found was $82.82 \mathrm{~ms}(\mathrm{SD}=17.55 \mathrm{~ms}$ ), with a range between 31.66 and $131,56 \mathrm{~m}$ ms. Again, it is close to the round $80 \mathrm{~ms}$ pointed by Lisker and Abramson (1964), with values between 50 and $135 \mathrm{~ms}$, and to the $86 \mathrm{~ms}$ by Chao and Chen (2008). However, as in the previous cases, it distances from the round $62 \mathrm{~ms}$, with values between $30 \mathrm{~ms}$ and $150 \mathrm{~ms}$, considered by Docherty (1992).

\subsection{Experimental group}

\subsubsection{The bilabial voiceless stop}

The experimental group presented a mean value of $31.51 \mathrm{~ms}(\mathrm{SD}=19.29 \mathrm{~ms})$ for $/ \mathrm{p} /$, with a range between $7.33 \mathrm{~ms}$ and $84.22 \mathrm{~ms}$, lower than the $56.95 \mathrm{~ms}(\mathrm{SD}=$ $14.76 \mathrm{~ms}$ ) reported for the SSBE-controls. A Pearson's correlation revealed a strong positive correlation between the production for $/ \mathrm{p} /$ and LOR, indicating that values for the bilabial stop increase as LOR increases $(r=.66, \mathrm{p}$ $<.05)$. Given the normal and homogeneous distribution of the data, 5 a T-test for Independent Samples revealed a significant difference between Brazilian immigrants and English monolinguals for the production of $/ \mathrm{p} /$, $t(20)=3,976, \mathrm{~N}=22, \mathrm{p}<.001$, with a large substantive significance/effect size $(r=0.61)$, with English natives presenting the highest VOT values. In general, even though bilinguals' production increases in time, it is different from the monolinguals' one. Table 2 presents English VOT mean values for the immigrants divided into our three experimental subgroups of LOR ( 0 -3 years; 4-7; and 8-11). SSBE monolinguals' values were added to the tables and figures for simple comparisons only.

Table 2. English VOT values for $/ \mathrm{p} /$.

\begin{tabular}{lll}
\hline Group & Mean value $(\mathrm{ms})$ & Range $(\mathrm{ms})$ \\
\hline LOR 0-3 & $20.75(\mathrm{SD}=12.22)$ & $7.33-65.05$ \\
LOR 4-7 & $27.21(\mathrm{SD}=14.22)$ & $7.89-71.81$ \\
LOR 8-11 & $46.56(\mathrm{SD}=20.24)$ & $10.66-84.22$ \\
SSBE-controls & $56.95(\mathrm{SD}=14.76)$ & $25.96-90.97$ \\
\hline
\end{tabular}

Table 2 reveals an increase in VOT values for English-L2 as well as in standard deviation values, that is, an increase in the variability of data. For $/ \mathrm{p} /$, based on the value for LOR 0-3 (20.75 ms), there is an increase of $31 \%$ in the mean value found for LOR 4-7 (27.21 $\mathrm{ms}$ ), and an increase of $124 \%$ for LOR 8-11 (46.56 ms). Corroborating our description, a Spearman's correlation reveals a strong positive monotonic correlation between the groups and the production for $/ \mathrm{p} /\left(r_{\mathrm{s}}=.71, \mathrm{p}<.01\right)$. Figure 1 makes this increase clearer.

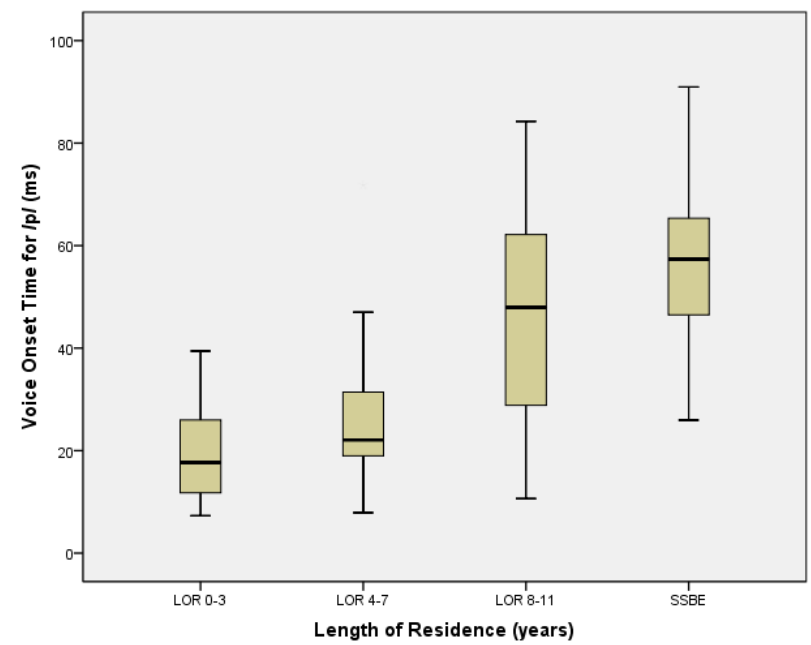

Fig. 1. Boxplot of the VOT values for $/ \mathrm{p} /$. 
An increase in the dispersion and in the variability of the data as a function of LOR can be perceived. LOR 8-11 presents a central tendency almost within the same range for the SSBE control group, revealing to be more inclined to higher VOT values than LOR 0-3 and LOR 4-7 and with a high dispersion and variability, inherent to bilingual production. Thus, in descriptive terms, the longer the LOR, the higher the VOT duration tendency and the dispersion of the data.

Considering normally distributed data $(\mathrm{p}>.05)$, a one-way Analysis of Variance (ANOVA) revealed that there is a significant difference for $/ \mathrm{p} /$ values between groups, $F(3,18)=9.866, \mathrm{~N}=22, \mathrm{p}<.001$, with a plainly evident effect $\left(\eta^{2}=.78\right)$. When compared with the control group, the Gabriel's pairwise comparisons test indicated that there were statistically significant differences for LOR 0-3 ( $<$.05) and LOR 4-7 ( $<<.05)$, while LOR 8-11 showed no differences $(p>.05)$. By contrasting only the immigrant groups with one another, LOR 0-3 did not present differences when compared with LOR 4-7 ( $\mathrm{p}>.05$ ), but presented differences in relation to LOR 8-11 ( $\mathrm{p}<.05)$. LOR 4-7 did not present differences in comparison with LOR 8-11 ( $\mathrm{p}>.05$ ), possible evidence that VOT values increased along with LOR.

In sum, the group with the longest LOR in London presented VOT values for $/ \mathrm{p} /$ that are in agreement with those expected for SSBE monolinguals. Our data then are in line with those of Sancier and Fowler (1997), who point out that BP speakers are able to achieve native-like English production, at least as far as VOT is concerned. The data also point to the postulates of Flege (1995) and Best and Tyler (2007) that learning mechanisms and processes remain intact in the life of an individual, and that phonetic categories evolve in time, also validating language as a CAS, as to van Gelder and Port (1995), it presents changes in time.

\subsubsection{The coronal voiceless stop}

For the coronal stop, the mean value $(\mathrm{N}=216)$ found was $47.87 \mathrm{~ms}(\mathrm{SD}=25.16 \mathrm{~ms})$, with a range between 7.70 and $123.30 \mathrm{~ms}$, relatively lower than the $77.31 \mathrm{~ms}$ (SD $=16.82 \mathrm{~ms}$ ) found for the SSBE controls. A Pearson's correlation revealed a moderate positive correlation between the production for $/ \mathrm{t} /$ and LOR, suggesting that values for the coronal stop increase in time $(r=.58, \mathrm{p}$ $<.05)$. Given the normally distributed data $(\mathrm{p}>.05)$, a T-Test for Independent Samples revealed a significant difference between the production by Brazilian immigrants and by English monolinguals, $t(20)=3,966$, $\mathrm{N}=22, \mathrm{p}<.01$, with a large effect size $(r=.68)$, in which English natives yielded the highest VOT values. Thus, bilinguals' English-L2 production is not similar to native English. Table 3 presents the English VOT mean values for our three experimental subgroups.

Table 3. English VOT values for $/ \mathrm{t} /$.

\begin{tabular}{lll}
\hline Group & Mean value $(\mathbf{m s})$ & Range $(\mathbf{m s})$ \\
\hline LOR 0-3 & $30.90(\mathrm{SD}=16.30)$ & $7.70-94.08$ \\
LOR 4-7 & $49.03(\mathrm{SD}=26.12)$ & $13.89-123.30$ \\
LOR 8-11 & $63.67(\mathrm{SD}=20.54)$ & $23.91-111.59$ \\
SSBE-controls & $77.31(\mathrm{SD}=16.82)$ & $31.58-113.37$ \\
\hline
\end{tabular}

As for the bilabial stop, there was an increase in the values for / $/$ / as LOR increased, confirming, in descriptive terms, our hypothesis that VOT would increase in time. Based on the production of LOR 0-3 $(30.90 \mathrm{~ms})$, there was an increase of $59 \%$ in the mean VOT value for LOR 4-7 (49.03 ms), and an increase of 106\% for LOR 8-11 (63.67 ms). Again, a Spearman's correlation revealed a strong positive monotonic correlation between groups and the production of / $\mathrm{t} /$ $\left(r_{s}=.68, \mathrm{p}<.05\right)$. Figure 2 shows an increase in the VOT tendency for LOR 4-7 and LOR 8-11.

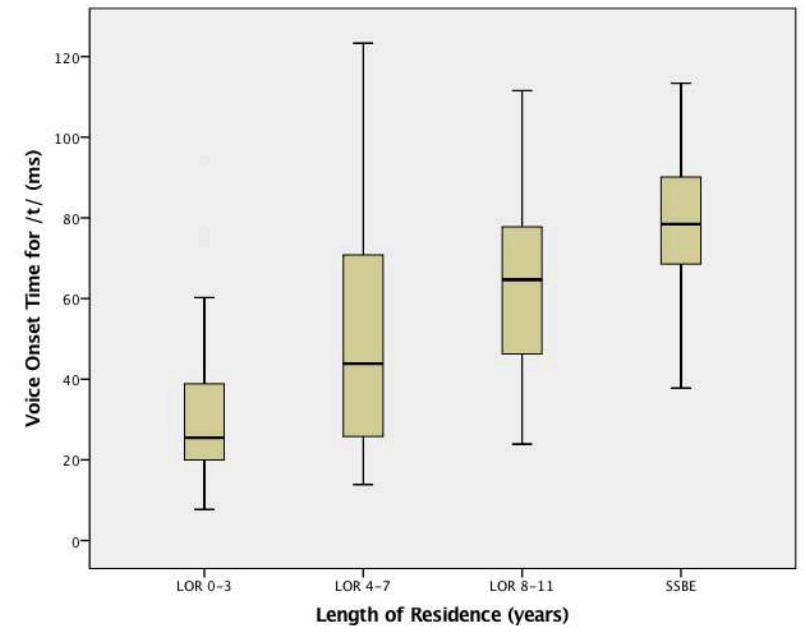

Fig. 2. Boxplot of the VOT values for /t/. 
With normally distributed data, a one-way ANOVA revealed that there was a significant difference among the groups in the values for / $\mathrm{t} /$ of English, $F(3,18)=$ $10.710, \mathrm{~N}=22, \mathrm{p}<.001$, with large magnitude of effect $\left(\eta^{2}=.80\right)$. Gabriel post hoc tests indicated that there was a statistically significant difference between the groups LOR 0-3 ( $<$.05) and LOR 4-7 ( $<$.05) when compared with English monolinguals, while LOR 8-11 did not present differences $(p>.05)$. By comparing only the groups of immigrants, LOR $0-3$ showed no difference when contrasted to LOR 4-7 ( $\mathrm{p}>.05$ ), but presented differences when compared with LOR 8-11 $(\mathrm{p}<.05)$, and LOR $4-7$ showed no differences $(\mathrm{p}>.05)$ to the group with the longest LOR in England. These data indicate gradience in developing the voiceless stops categories for English-L2, confirming again our core hypothesis that VOT duration would grow as LOR increased.

There was an increase in the VOT values for the coronal in immigrants' production over time in the new speech community, and the group with the longest immigration time presented English-L2 values that did not differ from the SSBE monolinguals ( $p>.05)$. As for the bilabial stop, again, the data corroborate Sancier and Fowler (1997) that late bilinguals are able to produce English with native-like values in an immigration context, and also corroborate a complex perspective to language (Beckner et al., 2009).

\subsubsection{The velar voiceless stop}

The mean VOT value found for $/ \mathrm{k} /(\mathrm{N}=216)$ was $68.35 \mathrm{~ms}$ ( $\mathrm{SD}=23.09 \mathrm{~ms}$ ), ranging from $23.76 \mathrm{~ms}$ to $132.95 \mathrm{~ms}$, smaller than $82.55 \mathrm{~ms}(\mathrm{SD}=18.05 \mathrm{~ms})$ yielded by the SSBE monolinguals. As for the other initial stops, a Pearson's correlation revealed a strong positive correlation between the production for $/ \mathrm{k} /$ and LOR, suggesting that the values increased as a function of time in London $(r=.68, \mathrm{p}<.05)$. Given the normally distributed data, a T-test for Independent Samples revealed that there were significant differences in the production of the velar stop among the groups, $t(20)=$ $1.874, \mathrm{~N}=22, \mathrm{p}<.05$, with the control group showing the highest VOT values, with a large effect size $(r=.62)$.
Table 4 details the VOT values for our participants divided into groups of LOR.

Table 4. English VOT values for $/ \mathrm{k} /$.

\begin{tabular}{lll}
\hline Group & Mean value (ms) & Range $(\mathbf{m s})$ \\
\hline LOR 0-3 & $50.21(\mathrm{SD}=16.21)$ & $28.57-98.39$ \\
LOR 4-7 & $70.69(\mathrm{SD}=23.24)$ & $23.76-116.11$ \\
LOR 8-11 & $84.18(\mathrm{SD}=14.76)$ & $50.04-132.96$ \\
SSBE-controls & $82.55(\mathrm{SD}=18.05)$ & $31.66-131.56$ \\
\hline
\end{tabular}

As in our previous analyses, there was an increase in the mean values as LOR increased. Based on the mean value for LOR 0-3 (50.21 ms), there was an increase of $41 \%$ in the mean value for LOR 4-7 (70.69 $\mathrm{ms})$, and 68\% for LOR 8-11 (84.18 ms), confirming, in descriptive terms, our core hypothesis. A Spearman's test revealed a strong positive monotonic correlation between groups and the production for $/ \mathrm{k} /\left(r_{s}=.71, \mathrm{p}<.01\right)$.

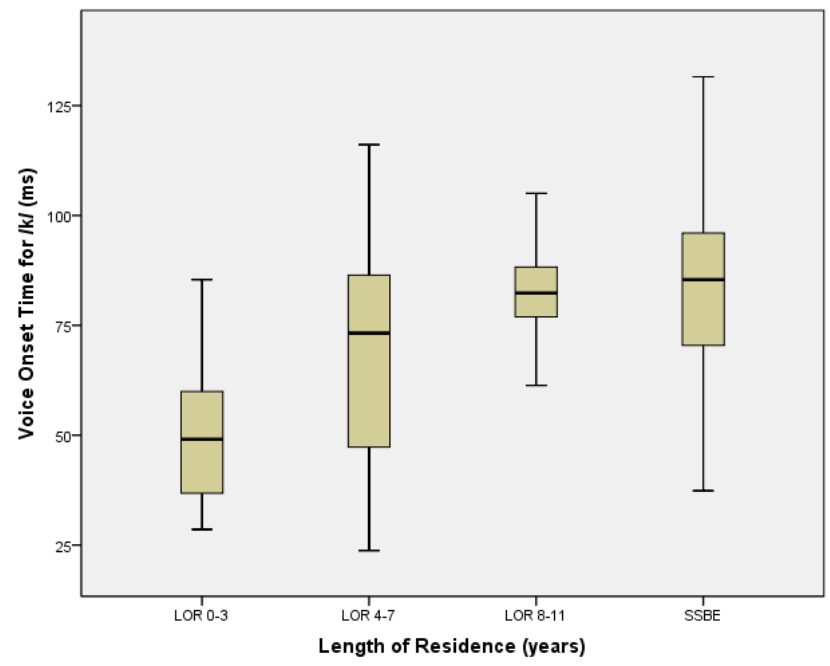

Fig. 3. Boxplot of the VOT values for $/ \mathrm{k} /$.

In figure 3, there is a rise in the central tendency of the data distribution. LOR 8-11 reveals a central tendency within the English monolinguals' one, yielding a lower data dispersion and variation, what lead us to think in a more advanced language development for that English VOT category.

With normal and homogeneous distribution of the data, a one-way ANOVA was carried out for the VOT means and revealed a significant difference in the 
values of $/ \mathrm{k} /$ for English among immigrant and native productions, $F(3,18)=5.599, \mathrm{~N}=22, \mathrm{p}<.05$, with a large magnitude of effect $\left(\eta^{2}=.82\right)$. Gabriel post hoc procedure pointed out that there was a statistically significant difference $(\mathrm{p}<.05)$ when LOR $0-3$ was compared with English monolinguals. On the other hand, LOR 4-7 ( $p>.05)$ and LOR 8-11 ( $>$ > .05) did not present statistically significant differences. When compared with each other, LOR 0-3 presented no difference in relation to LOR 4-7 ( $p>.05)$, but again, it was statistically different from LOR 8-11 $(\mathrm{p}<.05)$. LOR 4-7 presented no differences when compared to LOR 8-11 ( $>$ > .05). As in the previous cases, there was a tendency to increased VOT values over time. In sum, the two groups with the greatest LOR in London showed a VOT production for the velar stop statistically similar to a native English production, supporting the hypothesis of native-like production by late integrated bilinguals.

\section{Discussion}

In the 1990s, according to Schoofs (2013), the role of complexity changed, as it became a new paradigm for understanding the nature of human cognition and its processes. Language research then started using this perspective to analyze the most diverse natural language phenomena (e.g., Larsen-Freeman, 1997; Larsen-Freeman \& Cameron, 2008; Beckner et al., 2009, Kupske \& Alves, 2016). In a Complex perspective, the relationship between individuals and the environment, which provides patterns (samples) to be followed (Gibson, 1979), is sine qua non for language development, as any behavior of a speaker is a result of a range of competing factors, including social motivational ones. It is the social interaction between immigrants and their host speech community that leads to linguistic changes at all levels, which is corroborated by Yialmaz and Schmid (2015), as integration with the host community and language is one of the best strategies to L2 proficiency by immigrants, as integrated bilinguals interact with the host country native speakers, and adopt the host values and way of life in addition to theirs, which is reported to be extremely important to the development of the $\mathrm{L} 2$ pronunciation
(Flege, 2003). For that reason, our core hypothesis was that integrated Brazilian immigrants' VOT duration for English-L2 would increase as LOR increased, as the L2 level upon the immigration was rudimentary, which was confirmed with positive correlations between LOR and VOT production for all stops tested.

As all informants were proficient or near proficient in English at the testing, we can also hypothesize that even adults continue to tune their L2 speech production during their life span. This is evidence that languages are constantly being modified by the speakers' interactions, since linguistic constructions are developed by the engaging in real communicative acts through interpersonal communicative processes in addition to the cognitive ones, which is expected for integrated bilinguals.

Our initial core hypothesis also stated that participants with the longest LOR would yield the longest VOT mean values, and possibly within the SSBE range of production. For the three stops analyzed, LOR 8-11 presented a statistical performance that was not different from the monolingual group ( $\mathrm{p}>$ .05). LOR 4-7 presented a non-significant statistical difference to the native one in the velar production only $(\mathrm{p}>.05)$. LOR $0-3$, on the other hand, always presented differences when compared with the SSBE monolinguals $(\mathrm{p}<.05)$. We can note a development of English VOT values closer to the native standards over the years of residence. An evidence is the fact that the group LOR 4-7 presented statistical differences when compared with English controls for $/ \mathrm{p} /(\mathrm{p}<.05)$ and $/ \mathrm{t} /(\mathrm{p}<.05)$, but did not present differences when compared with the LOR 8-11 ( $\mathrm{p}>.05)$ that, in turn, did not present differences when compared to SSBE monolinguals $(\mathrm{p}>.05)$. Moreover, as for $/ \mathrm{k} /$, LOR 4-7 presented values close to the controls ( $p>.05)$, so we can speculate that the VOT category for the English velar stop may develop earlier towards L2 native values than the other ones. A possible explanation would be that the velar stop has the longest VOT duration and, as a consequence, the greatest perceptual salience.

In light of our data, we can retake Grossberg (1995), who emphasizes that complex systems are adaptive and self-structuring, responding continuously 
and adaptively to environmental changes. There is, therefore, more indication that language is a CAS, since it moves, changes, evolves over time. By attesting an increase in VOT values for English-L2 as a function of LOR, we provide empirical data supporting that languages are not linear and, much less, represent closed and rigid systems. Our data description also highlights the characteristics of CAS in general. We emphasize two of them: (i) that speaker's behaviors are consequences of competing factors, ranging from perceptual restrictions to social motivations, and (ii) that language structures emerge from interrelated patterns of empiric experiences, social interaction and cognitive mechanisms.

Furthermore, for years it was believed that age of $\mathrm{L} 1$ and $\mathrm{L} 2$ development was the central variable for speech production, due to Lennenberg's (1967) Critical Period Hypothesis $(\mathrm{CPH})$ for language acquisition, for instance. Such hypothesis proposed that there was an optimal period for language development, suggesting that older learners were constrained to present a foreign accent in the L2, as, after that period, it would be impossible to achieve native-like production. Subsequent studies contradicted this hypothesis, Flege (1995, 2003, 2007), and Best and Tyler (2007), for instance, propose that the cognitive mechanisms for learning and adjusting the phonemic system would remain intact during the whole lifespan. However, even though early and late learners have the same neural plasticity, L1 phonemic categories are more robust and entrenched in late bilinguals, making it harder to develop an L2 category in adulthood, but not impossible as we may infer from the data of Brazilian immigrants in this study, at least with regard to VOT production.

\section{Conclusions}

This study sought to analyze the production of word-initial voiceless stops by Brazilian immigrants residing in London, and demonstrated that linguistic categorization processes are constant, and that even adult grammars are not rigid, with potential and plasticity to change in relation to new inputs/ experiences/environment. Therefore, this study validates those against the hypothesis that mechanisms for the L2 development operate differently from those applied to the L1 (e.g., Beckner et al. 2009; Herdina \& Jessner, 2002; Flege 1995; Best \& Tyler, 2007). It also advocates language and language development as complex adaptive systems, as they are dynamic and in constant change in synchrony to the speaker's experience and environment.

\section{Acknowledgements}

I would like to acknowledge all contribution and support received from my former doctoral advisor Dr Ubiratã Kickhöfel Alves, as this paper is based on fragments of my doctoral dissertation defended at Universidade Federal do Rio Grande do Sul in 2016. I also thank Dr Bronwen Evans (University College London) for supervising me during my period at UCL, and the anonymous reviewers for helpful comments on this manuscript.

\section{Funding}

This research received funding for the data collection in London by the Coordination for the Improvement of Higher Level Personnel (CAPES - BEX 6542/14-0) 


\section{Notes}

1. In this work, we use phonetic and phonological transcriptions to facilitate the reading of the data. However, they represent a theoretical conception that is distinct from the one we assume. In a complex view of language, coadunate with usage-based theories, the separation of phonetic and phonological levels would be a contradiction.

2. Ethics Research Committee approval: 129884/2015.

3. Initially, 22 Brazilian volunteers were recruited, but 10 were dropped from the experiment because they revealed to be not proficient or near proficient in English, because they had weak connections to the L1 or the L2 language and culture, or had abandoned the L1 culture completely.

4. To minimize any bias of speech rate, the whole inferential statistics was also conducted with relative VOT values. To do so, the VOT duration was measured and then relativized to the length of its carrier sentence. As both absolute and relative VOT tests produced similar results, we decided to present only the absolute values and tests.

5. Kolmogorov-Smirnov and Shapiro-Wilk tests were used to verify the normality of the data.

\section{References}

Beckner, C., Blythe, R., Bybee, J., Christiansen, M. H., Croft, W., Ellis, N. C.; Holland, J., Ke, J.; LarsenFreeman, D., \& Schoenemann, T.. (2009) Language is a complex adaptive system: position paper. Language Learning, 59 (1), 1-26.

Best, C., \& Tyler, M. (2007). Nonnative and secondlanguage speech perception: Commonalities and complementarities. In M. Munro \& O. Bohn (Org.), Language experience in second language speech learning: The role of language experience in speech perception and production (pp. 13-34). Amsterdam: John Benjamins.

Birdsong, D. (2005). Interpreting age effects in second language acquisition. In J. Kroll \& A. M. B. de Groot (Eds.), Handbook of bilingualism: Psycholinguistic perspectives (pp. 109-127). Oxford: Oxford University Press.

Bohn, O., \& Flege, J. E. (1993). Perceptual switching in Spanish/English bilinguals. Journal of Phonetics, 21, 267-290.

Boersma, P., \& Weenink, D. (2015). PRAAT: Doing phonetics by computer (Computer Software). University of Amsterdam, The Netherlands.

Bongaerts, T., Summeren, C., Planken, B., \& Schils, E. (1997). Age and ultimate attainment in the production of foreign language. Studies in Second Language Acquisition, 19, 447-65.
Bybee, J. (2001). Phonology and Language Use. Cambridge: Cambridge University Press.

Chao, K., \& Chen, L. (2008). A cross-linguistic study of Voice onset time in stop consonant production. Computational Linguistics and Chinese Language Processing. 13 (2), 215-232.

Chiswick, B. R., \& Paul, W. (2001). A Model of Destination Language Acquisition: Application to Male Immigrants in Canada. Demography 38 (3), 391-409.

Cohen, G. (2004) The VOT dimension: A bi-directional experiment with English and Brazilian-Portuguese stops. (Master's thesis) Universidade Federal de Santa Catarina, Florianópolis, Brazil.

de Bot, K., Lowie, W., \& Verspoor, M.H. (2007) A Dynamic Systems Theory approach to second language acquisition. Bilingualism: Language and Cognition 10 (1), 7-21.

de Leeuw, E. (2014). Maturational constraints in bilingual speech. In E. M. Thomas \& I. Mennen (Eds.), Advances in the study of bilingualism (pp.25-37). Bristol: Multilingual Matters.

Docherty, G. J. (1992). The timing of voicing in British English obstruents. Berlin: Foris.

Ellinger, B. (2000). Therelationshipbetween ethnolinguistic identity and English language achievement for native Russian speakers and native Hebrew speakers in Israel. Journal of Multilingual and Multicultural Development, 21(4), 292-307.

Ellis, N. C. (2008) The dynamics of language use, language change, and first and second language acquisition. Modern Language Journal, 41(3), 232-249.

Flege, J. E. (1995). Second language speech learning: Theory, findings, and problems. In W. Strange (Ed.), Speech perception and language experience: Issues in cross-language research (pp. 233-277). Baltimore: York Press.

(2002). Interactions between the native and second-language phonetic systems. In P. Burmeinster, T. Piske \& A. Rohde (Eds.), An integrated view of language development: Papers in honor of Henning Wode (pp. 217-244). Trier, Germany: Wissenschaftlicher Verlag.

(2003). Methods for assessing the perception of vowels in a second language. In E. Fava \& A. Mioni (Eds.), Issues in clinical linguistics (pp. 19-44). Padova: UniPress.

(2007). Language contact in bilingualism: Phonetic system interactions. In J. Cole \& J. Hualde (Eds.), Laboratory phonology, 9 (pp. 353-382) Berlin, Germany: Walter de Gruyter. 
Flege, J. E., Schirru, C., \& MacKay, I. (2003) Interaction between the native and second language phonetic subsystems. Speech Comm., 40, 467-491.

Gibson, J. (1979). The ecological approach to visual perception. Boston: Houghton Mifflin.

Grossberg, S. (1995). Neural Dynamics of Motion Perception, Recognition Learning, and Spatial Attention. In R. F. Port \& T. van Gelder (Eds.), Mind as Motion: Explorations in the Dynamics of Cognition (pp. 449-489). Cambridge, Massachusetts; London, England: MIT Press.

Haugen, E. (2001). The ecology of language. In A. Fill \& P. Mühlhäusler (Orgs.) The ecolinguistics reader (pp. 5766). London: Continuum.

Herdina, P., \& Jessner, U. (2002). A Dynamic Model of Multilingualism. Perspectives of Change in Psycholinguistics. Clevedon, Buffalo, Toronto, Sydney, Multilingual Matters.

Keijzer, M. (2007). Last in First out? An Investigation of the Regression Hypothesis in Dutch Emigrants in Anglophone Canada. (PhD Dissertation) English Department, Vrije Universiteit, Amsterdam.

Kupske, F. (2016). Imigração, Atrito e Complexidade: a produção das oclusivas surdas iniciais do inglês e do português por brasileiros residentes em Londres. (Doctoral Dissertation) Universidade Federal do Rio Grande do Sul, Porto Alegre, Brazil.

Kupske, F., \& Alves, U. K. (2016). A fala de imigrantes brasileiros de primeira geração em Londres como evidência empírica para a língua como um Sistema Adaptativo Complexo. ReVEL, 14 , n. 29, 173-203.

Johnson, J. S., \& Newport, E. L. (1989). Critical period effects in second language learning: The influence of maturational state on the acquisition of English as a second language. Cognitive Psychology, 21(1), 60-99.

Ladefoged, P. (2001). A Course in Phonetics. 4. ed. Boston: Heinle \& Heinle.

Larsen-Freeman D. (1997), Chaos / Complexity Science and Second Language Acquisition. Applied Linguistics, 18 (2), 141-165.

Larsen-Freeman D., \& Cameron, L. (2008). Complex systems and Applied Linguistics. Oxford: Oxford University Press.

Lenneberg, E. (1967). Biological Foundations of Language, New York: Wiley.

Lisker, L., \& Abramson, A.S. (1964). A cross-language study of voicing in initial stops: Acoustical measurements. Word, 20 (3), 384-422.

McCarthy, K. M., Evans, B., \& Mahon, M. (2013). Acquiring a second language in an immigrant community: The production of Sylheti and English stops and vowels by London-Bengali speakers. Journal of Phonetics, 41, 344-358. DOI:10.1016/jwocn.2013.03.006

Major, R. C. (1992). Losing English as a first language. The Modern Language Journal, 76 (2), 190-208.

Mercer, S. (2013). Towards a complexity-informed pedagogy for language learning. Rev. Brasileira de linguística aplicada. [online], 13 (2), 375-398.

Muñoz, C., \& Singleton, D. (2007). Foreign accent in advanced learners. Two successful profiles. The EUROSLA Yearbook 7, 171-190.

Opitz, C. (2011). First language Attrition and Second Language Acquisition in a Second- Language Environment. ( $\mathrm{PhD}$ dissertation), Trinity College Dublin.

(2013) A dynamic perspective on late bilinguals' linguistic development in an L2 environment. International Journal of Bilingualism, 12 (17), 701-715. DOI:10.1177/1367006912454621

Rasinger, S. M. (2005). Age of Arrival and Second Language Acquisition of English Copula and Auxiliary Constructions:A Study on BengaliEnglish in East London. ISB4: Proceedings of the 4th International Symposium on Bilingualism, ed. James Cohen, Kara T. McAlister, Kellie Rolstad, and Jeff MacSwan, 1910-1920. Somerville, MA: Cascadilla Press.

Sancier, M. L., \& Fowler, C. A. (1997). Gestural drift in a bilingual speaker of Brazilian Portuguese and English. Journal of Phonetics, 27 (4), 421-436.

Schmid, M. S. (2011). Language Attrition. Cambridge: Cambridge University Press (Key Topics in Sociolinguistics series).

Schmid, M. S., Gilbers, S., \& Nota, A. (2014). Ultimate attainment in late second: Phonetic and grammatical challenges in advanced Dutch-English bilingualism. Second language research, 30(2), 129-157. DOI: $10.1177 / 0267658313505314$

Schoofs, P. (2013). The mutual influence of the first and second languages in German and English L1 speakers in second language environments. (PhD dissertation) University of Newcastle Upon Tyne.

Schwartzhaupt, B. M. (2015). Testing Intelligibility in English: the effects of positive VOT and contextual information in a sentence transcription task. (Master's thesis) Universidade Federal do Rio Grande do Sul, Porto Alegre, Brazil.

Slobin, D. (1977). Language change in childhood and in history. In J. Mcnamara (Ed.), Language Learning and Thought (pp. 185-214). London: Academic Press.

Stevens, G. (2006). The Age-Length-Onset Problem in 
Research on Second Language Acquisition Among Immigrants. Language Learning, 56 (4), 671-692. DOI:10.1111/j.1467-9922.2006.00392.x

van Gelder, T., \& Port, R. (1995). It's about time: an overview of the dynamics approach to cognition. In R. Port \& T. van Gelder (Eds.), Mind as motion: Explorations in the Dynamics of Cognition (pp. 1-43). Cambridge, MA: The MIT Press.

van Tubergen. (2010). F. Determinants of second language proficiency among refugees in the Netherlands. Social Forces, 89(2), 515-534.

van Tubergen F., \& Wierenga, M. (2011). The language acquisition of male immigrants in a multilingual destination: Turks and Moroccans in Belgium. Journal of Ethnic and Migration Studies, 37(7), 1039-1057.

Williams, G. P. (1997). Chaos theory tamed. Washington, D.C.: Joseph Henry Press.

Yllmaz, G., \& Schmid, M. (2015). Second Language Development in a Migrant Context: Turkish community in the Netherlands. International Journal of the Sociology of Language 236: 101-132.

Recebido em: 31/03/2017 Aceito em: 06/07/2017 